Portland State University

PDXScholar

\title{
Attempts to Synthesize Fumarylacetoacetate Using the Filamentous Ascomycete, Aspergillus nidulans
}

\author{
Carolyn Loughran \\ Portland State University
}

Follow this and additional works at: https://pdxscholar.library.pdx.edu/honorstheses

\section{Let us know how access to this document benefits you.}

\section{Recommended Citation}

Loughran, Carolyn, "Attempts to Synthesize Fumarylacetoacetate Using the Filamentous Ascomycete, Aspergillus nidulans" (2018). University Honors Theses. Paper 596.

https://doi.org/10.15760/honors.606

This Thesis is brought to you for free and open access. It has been accepted for inclusion in University Honors Theses by an authorized administrator of PDXScholar. Please contact us if we can make this document more accessible: pdxscholar@pdx.edu. 
Attempts to Synthesize Fumarylacetoacetate Using the Filamentous Ascomycete, Aspergillus nidulans

\section{By Carolyn Loughran}

An undergraduate honors thesis submitted in partial fulfillment of the requirements for the degree of Bachelor of Science in University Honors and Biology

Thesis Advisor: Sean Nygaard, B.S.

Special thanks to Dr. Markus Grompe and Dr. Fernández-Cañón

Portland State University 


\begin{abstract}
Fumarylacetoacetate (FAA) is a downstream metabolite of phenylalanine catabolism. In Human Type 1 Tyrosinemia a deletion of the enzyme that breaks down this compound leads to a toxic build up that leads to acute liver and kidney failure. FAA is used to test the activity of a drug used liver repopulation therapy. This project aims to synthesize this compound using enzyme extracts from the filamentous fungi Aspergillus nidulans. The fungus is grown on a carbon source, phenylacetic acid, which induces expression of enzymes in the phenylalanine catabolic pathway. The enzymes are then extracted from the cultures, purified, and used in an enzyme assay converting the metabolite homogentisate (HGA) to maleylacetoacetate (MAA). MAA is then isomerized to FAA via the addition of metaphosphoric acid (MPA). This report outlines attempts to synthesize this compound and the troubleshooting techniques employed.
\end{abstract}

\title{
Introduction
}

The phylum of fungi Ascomycota consists of over 30,000 species including both unicellular and multicellular organisms[19]. Ascomycetes have both vegetative and reproductive stages, and spend most of their life cycles with haploid genomes, although they can be diploid during certain life phases $[9,19]$. Multicellular ascomycetes, such as the filamentous fungi Aspergillus nidulans, have drastically different morphologies during different life cycles and can alternate between these depending on outstanding conditions (Figure 1). When submerged in liquid culture, Aspergillus nidulans exists as vegetative bodies collectively known as mycelium. These cells are generally haploid, but can fuse with other genetically distinct hyphae to form either binucleate, or occasionally diploid mononucleated cells (Figure 1). When a colony of mycelium 
is exposed to air, they undergo conidiation [19]. This process leads to the production of asexual spores known as conidia. Ascomycetes can also undergo sexual reproduction during which fruiting bodies known as cleistothecia containing meiotically derived ascospores form (Figure 1). Cleistothecia are generally homothallic, meaning that ascospores from one fruiting body will generally mate with other spores within the same mycelium [27].

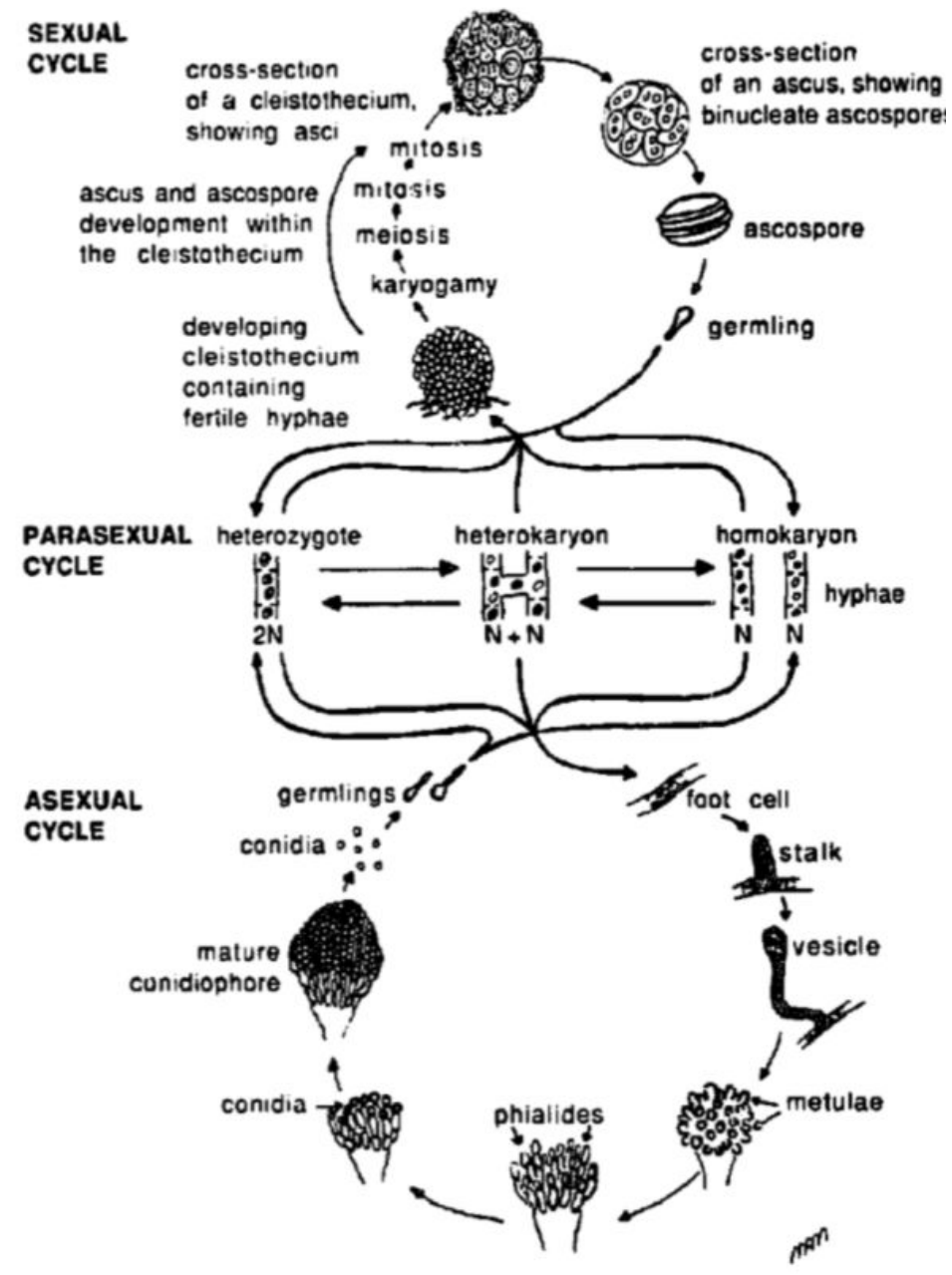

Figure 1. Life cycle of $\boldsymbol{A}$. nidulans taken from Timberlake and Marshall [27].

Some ascomycete species are pathogens, causing human illnesses such as pneumonia, while others are notable for their utility. Many are used in food and drink production, such as bakers and brewers yeasts. Other ascomycetes are used in medical and research settings for producing 
enzymes and antibiotics such as penicillin [19, 27]. In research, ascomycetous fungi are valuable as model organisms for the study of biological processes, with some of the most common model organisms in molecular and cell biology being Saccharomyces cerevisiae and Neurospora crassa. Aspergillus nidulans is a filamentous fungus that is used as model organism for the study of multicellular eukaryotic systems[19, 27].

Aspergillus nidulans possesses several characteristics that make it particularly suited to genetic analysis and manipulation. For example, a haploid, single nucleate mycelium (homokaryon) can fuse with hyphae from another, genetically distinct homokaryon to form cells that contain the nuclei of both parents (heterokaryon) (Figure 1). This property means that two genetically distinct strains, if combined, will spontaneously form heterokaryon that can be easily isolated by simple complementation experiments. A. nidulans is also very susceptible to DNA mediated transformation, which can induce site directed mutations that can also be detected by complementation tests $[20,23,27,28]$. A. nidulan's relatively fast life cycle and simple nutritional needs further contribute to its utility as a model organism for studying biological processes in multicellular eukaryotes.

One such use has been illustrated by Fernández-Cañón, J. M. and Peñalva, M. A, who employed A. nidulans to characterize several of the genes encoded in the phenylalanine (Phe) metabolic pathway (Figure 2). Aspergillus nidulans is well suited for the study of catabolic pathways because each pathway is only induced in the presence of the proper transcriptional activator, and therefore it is possible to control gene expression in a pathway via the addition or withdrawal of specific nutrients $[20,22,23,28]$. 
Genetically based defects in the enzymes of a metabolic pathway characterize autosomal recessive disorders that fall under the category of 'inborn errors of metabolism' [28]. These genetic diseases are of great interest to gene therapy researchers because they are often caused by a single mutated gene encoding one of the enzymes in the pathway. This makes them much easier to target when compared to many other genetically based diseases which have numerous environmental influencers in addition to mutated genes, all of which may directly or indirectly contribute to a disease phenotype.

The first inborn error of metabolism ever classified, alkaptonuria, results from a buildup of the intermediate phenylalanine metabolite homogentisate [23]. The buildup is caused by a mutation in the gene encoding homogentisate 1,2-dioxygenase (HGD), enzyme IV in the phenylalanine metabolic pathway (Figure 2). The disease has relatively mild symptoms, including black urine, and an increased risk of arthritis [23, 28]. Mutations in other enzymes in this pathway have far more severe effects, leading to diseases such as phenylketonuria (PKU) and tyrosinemia which lead to rapid neurological deterioration and often death soon after birth if not treated [Figure 2]. 


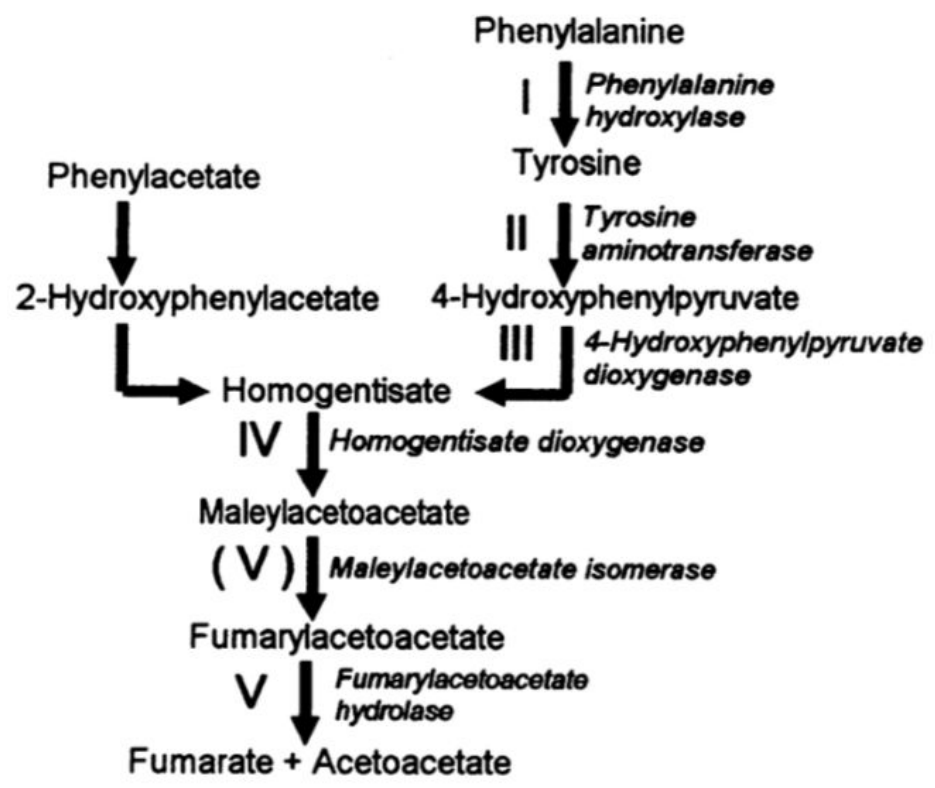

Figure 2. The phenylalanine pathway for humans and $A$. nidulans. The phenylacetate pathway is only present in $\boldsymbol{A}$. nidulans. Numerals correspond to disorders caused by knockout of each enzyme: I, phenylketonuria and phenylalaninaemias; II, type II tyrosinemia; III type III tyrosinemia; IV alkaptonuria; V hereditary type I tyrosinemia. Figure taken from Fernández-Cañón and Peñalva [28].

Fernández-Cañón, J. M. and Peñalva, M. A. were interested in studying inborn errors of metabolism in the phenylalanine pathway. They constructed a protocol for growing $A$. nidulans and extracting the enzymes involved in phenylalanine pathway for further study [20, 22, 23, 28]. The procedure included creating strains of $A$. nidulans deficient in one of the enzymes in the pathway via DNA mediated transformation, termed a knockout strain. Protein extracts from these strains are used in spectrophotometric enzyme assays designed to detect, analyze, and utilize enzymatic activity $[20,22,23,28]$.

One use for the protocols they created is the production of fumarylacetoacetate (FAA), an intermediate metabolite in the Phe catabolic pathway that is broken down into its components by the fumarylacetoacetate hydrolase $(\mathrm{FAH})$ enzyme [28]. FAA is not available commercially, and 
it must therefore be made in the lab if required. This is accomplished by growing a strain of $A$. nidulans deficient in the FAH enzyme under nutritional conditions that activate the Phe pathway. Activation leads to increased expression of the enzymes encoded in the pathway. The enzymes are then extracted and purified. This extract is then used to convert the commercially available upstream metabolite homogentisic acid (HGA) into fumarylacetoacetate (FAA), the desired product [28].

Fumarylacetoacetate (FAA) is clinically significant as the compound that accumulates in a rare genetic disorder known as human type I tyrosinemia [4,5]. This toxic build up, caused by a deficiency in the phenylalanine metabolic enzyme FAH, leads to cirrhosis, human hepatocellular carcinoma, and kidney failure [4,5]. Patients with HT1 inherit a mutated copy of the fah gene from both parents making them homozygous recessive individuals.

FAA is also of interest in research for drug development in liver repopulation therapy. This can be seen in a recent paper published in Science Translational Medicine [5]. In this article, Nygaard et al. utilize the toxic nature of FAA build up in order to confer a selective advantage to genetically modified cells transplanted into a diseased liver. Liver repopulation therapy is the process by which patient cells that are corrected for a given mutation are implanted into a diseased liver with the intention that they will repopulate the liver with healthy cells [29]. In order for this method to be successful, the transplanted cells a must have a strong selective advantage over the host cells so that they can reach sufficient replication levels to nullify the disease symptoms. In type 1 tyrosinemia, a deficiency in the enzyme FAH causes a toxic build up of FAA $[5,28,29]$. This disease confers a strong selective advantage to hepatocytes that have working FAH enzymes [5, 29]. The approach taken by Nygaard et al. is to introduce an FAH 
inhibiting drug, called CEHPOBA, to the liver after the transplantation of genetically modified cells. The modified cells contain the therapeutic transgene, as well as a shRNA that confers resistance to CEHPOBA by blocking enzymatic activity further upstream of FAH in the pathway, leading to the build up of a less toxic intermediate metabolite (HGA). Nygaard et al. illustrate that this method can be used to confer a selective advantage to transplanted cells intended to correct inborn errors of metabolism and other genetic diseases that affect the liver [5].

The creation of a method to universally confer selective advantage to transplanted cells obviously has substantial clinical benefits and further study and optimization of this method is therefore warranted. New batches of the drug CEHPOBA need to be tested for effectiveness in vitro before being utilized in liver repopulation experiments. The drug is tested in an enzyme assay, similar to the assay used in the FAA synthesis protocol, wherein liver extract (generally mouse) containing FAH enzyme is combined with FAA and the drug CEHPOBA and placed in a spectrophotometer. If absorbance of light at $330 \mathrm{~nm}$ decreases over time, then FAH is hydrolysing FAA, which absorbs light at this wavelength [22]. In this case it's activity is therefore not being blocked by CEHPOBA. Alternatively, if there is no decrease in the absorbance measurement, this indicates that the CEHPOBA is blocking the FAH activity and is therefore suitable to be used in repopulation experiments. It is therefore critical to make stocks of FAA so that these assays can be run.

This thesis project was an attempt to make these FAA stocks. Attempts began in March of 2017 and as of May 2018 the protocol has still yet to be successfully run from start to finish. The 
following pages describe the basics of the protocol, as well as attempts to troubleshoot this very technically challenging process.

\section{Methods}

This protocol was based off procedures developed and shared by Dr. Fernández-Cañón [22, 23]. Fungal spores were stored in a $25 \%$ glycerol solution at $-80^{\circ} \mathrm{C}$. After being thawed, spores were grown on solid media plates containing (in g/l) agar (Apex: Bioresearch Products), 20; peptone $\left(\right.$ Bacto $\left.^{\mathrm{TM}}\right), 1$; malt extract $\left(\right.$ Bacto $\left.^{\mathrm{TM}}\right), 20$; glucose (Invitrogen), 15. $50 \mathrm{ul}$ of spore solution was added to each media plate. Spores were grown at $37^{\circ} \mathrm{C}$ for $2-3$ days and then harvested in $30 \mathrm{ml}$ of water with Tween $80,0.01 \% \mathrm{w} / \mathrm{v}$. This solution was vortexed and then stored overnight at $4^{\circ} \mathrm{C}$ before the spores were spun down at $7500 \mathrm{~g}$ in a Beckman J2-HC centrifuge for 20 minutes and resuspended in $30 \mathrm{ml}$ of pure water.

$6 \mathrm{ml}$ of spores were then inoculated into $400 \mathrm{ml}$ of defined growth media containing (in g/l) $\mathrm{KPO}_{4} \mathrm{H}_{2}$ (Research Products International Corp), 13.6; $\left(\mathrm{NH}_{4}\right)_{2} \mathrm{SO}_{4}$ (Millipore Sigma), 2.0; $\mathrm{MgSO}_{4} 7 \mathrm{H}_{2} \mathrm{O}$ (Fischer Scientific), 0.25; $\mathrm{FeSO}_{4} 7 \mathrm{H}_{2} \mathrm{O}$ (Acros Organics), $0.0005 ; \mathrm{CuSO}_{4} \cdot 5 \mathrm{H}_{2} \mathrm{O}$ (Fischer Scientific), glucose (Invitrogen), 0.3\% w/v; biotin (Fischer BioReagents), 0.001; and methionine (Sigma Aldrich), at $5 \mathrm{mM}$ final concentration. The $\mathrm{pH}$ of this media was adjusted to 7 via addition of $\mathrm{KOH}$ (Fischer Scientific) before inoculation with spores. Cultures were grown for 18 hours in a New Brunswick Scientific Excella E25 orbital shaker at $250 \mathrm{rpm}$. After this initial growth period, the fungus, now in the form of mycelium, were harvested via filtration, washed with 21 of Milli-Q water, and added to cultures containing all of the previous supplements except for glucose and shaken for 1 hour. Phenylacetic acid (Sigma Aldrich) was then added at a final concentration of $10 \mathrm{mM}$. The cultures were grown in the orbital shaker on phenylacetic acid 
as the sole carbon source for 4 hours before once again being harvested via filtration and rinsed with 21 of Milli-Q water. The mycelium was then resuspended in $50 \mathrm{mM}$ potassium phosphate buffer $\mathrm{pH} 7$ at a concentration of $1 \mathrm{~g}$ mycelia per $10 \mathrm{ml}$ of buffer. The mycelia were then mechanically broken open via sonication using five 10 second pulses with 1 minute breaks between using a Cole Parmer Ultrasonic Processor at $4{ }^{\circ} \mathrm{C}$. The resulting lysate was centrifuged at $13,000 \mathrm{~g}$ for $15 \mathrm{~min}$ at $4^{\circ} \mathrm{C}$ to clear away larger cell debris. This extract was then further clarified via passage through a PD-10 desalting column to form the final protein extract.

The protein extract was used in an enzyme assay designed to convert homogentisate (HGA) into maleylacetoacetate (MAA). The reaction was initially run in a $1 \mathrm{ml}$ pilot reaction before moving to the full scale $10 \mathrm{ml}$ reaction. The assay contained HGA (Tokyo Chemical Industry), 2 mM from $200 \mathrm{mM}$ stock; ascorbic acid (Fischer Scientific), $1 \mathrm{mM}$ from $100 \mathrm{mM}$ stock; $\mathrm{FeSO}_{4}$ (Acros Organics) $50 \mathrm{uM}$ from $50 \mathrm{mM}$ stock; protein extract (100 ul for pilot and $2 \mathrm{ml}$ for full size reaction), and $50 \mathrm{mM}$ potassium phosphate buffer $\mathrm{pH} 7$ added to bring final volume of reaction to desired volume, either $1 \mathrm{ml}$ for the pilot or $10 \mathrm{ml}$ for the full size reaction. The reaction was run in a $37^{\circ} \mathrm{C}$ water bath with oxygen bubbled in continuously throughout the reaction time. The progress of the reaction was monitored in a Thermo Scientific Nanodrop 2000c Spectrophotometer that tracked the conversion a $290 \mathrm{~nm}$ absorbance peak, representing HGA into a $330 \mathrm{~nm}$ peak, representing MAA. After complete conversion of the $290 \mathrm{~nm}$ peak into the 330 peak, Metaphosphoric acid (Sigma Aldrich), at 20\% w/v was added to precipitate out remaining proteins and isomerize MAA to FAA. The acidified mixture was kept overnight at $4^{\circ} \mathrm{C}$ before being neutralized with $\mathrm{KOH}$ to bring the $\mathrm{pH}$ to 7 . 


\section{Results}

After growing Aspergillus nidulans in phenylacetic acid to induce the phenylalanine pathway, a protein extract was made by breaking open the cells of the mycelium via sonication to release the intracellular components including the desired enzyme, homogentisate 1,2-dioxygenase (HGD). The extract was purified via centrifugation and passage through a PD-10 desalting column. This enzyme extract was then added to a reaction containing HGA, 2 mM from $200 \mathrm{mM}$ stock; ascorbic acid, $1 \mathrm{mM}$ from $100 \mathrm{mM}$ stock; $\mathrm{FeSO}_{4} 50 \mathrm{uM}$ from $50 \mathrm{mM}$ stock; protein extract (100 ul for pilot and $2 \mathrm{ml}$ for full size reaction), and $50 \mathrm{mM}$ potassium phosphate buffer $\mathrm{pH} 7$ added to bring the contents of the reaction to the desired volume of $1 \mathrm{ml}$ for the pilot reaction. The reaction was run at $37^{\circ} \mathrm{C}$ for 250 minutes. Figure 3 shows this first iteration of the enzyme assay run in the project. When the HGD enzyme converts homogentisate to maleylacetoacetate, the absorbance at $330 \mathrm{~nm}$ should increase substantially- from 0 to around $1.35 \mathrm{OD}$ according to the published protocols (Dr. Fernández-Cañón). The conversion within this assay fell far short of that with the highest absorbance read being 0.45 OD (Figure 3). Another concerning feature of this experiment was the amount of time taken for this minimal conversion to take place. Fernández-Cañón recalls a reaction time of between 15 to 20 minutes. This reaction was run for over two hours and reached levels of product around a third of what was expected (Figure 3). This indicates diminished enzyme activity. 


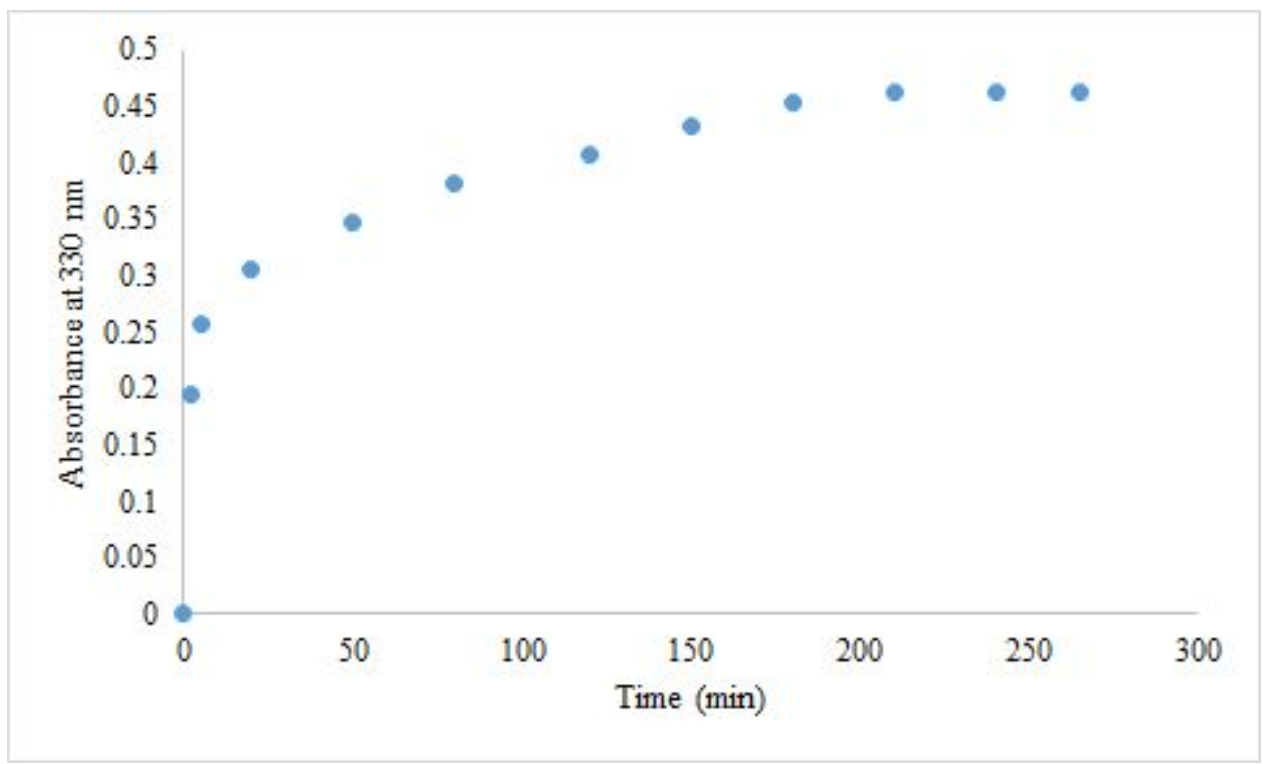

Figure 3. Change in absorbance at $330 \mathrm{~nm}$ in Nanodrop spectrophotometer for enzyme assay over time. 100 ul of enzyme extract from $A$. nidulans combined with $2 \mathrm{mM}$ HGA, $1 \mathrm{mM}$ ascorbate, $50 \mathrm{uM} \mathrm{FeS0}_{4}$ and potassium phosphate buffer $\mathrm{pH}$, and placed in a $37^{\circ} \mathrm{C}$ water bath with oxygen bubbled in for 250 minutes.

It was thought based on the data in Figure 3 that inadequate amounts of enzyme was extracted from the A. nidulans. It was hypothesized that this was due to inadequate breakage of the tough cell walls of the mycelium. In order to extract more enzyme from the mycelia, an alternative strategy of mechanical breakage was pursued. This involved using a French Pressure Cell Press, a machine that applies pressure up to 20,000 psi on to a sample in order to burst tough cell walls. The level of cell lysis was also measured by observing the mycelia under a light microscope using DAPI nucleic acid staining. If the DAPI was concentrated in the nucleus of the cells, it was taken to mean that lysis had not taken place (Figure 4A). However, if the dye was diffuse then it was assumed that the mycelia had burst (Figure 4B)

After verifying that the mycelia were properly burst in this way, the enzyme assay was rerun under the same conditions as the first iteration to test for increased activity (Figure 5). This experiment yielded around the same amount of overall conversion although it was in a shorter 
amount of time. After about 30 minutes, the peak absorbance at $330 \mathrm{~nm}$ was reached. Since the improved cell lysis measure did not improve yields of product, several other methods of increasing the concentration of HGD in the protein extract were attempted. These included increasing the amount of spores added liquid culture from $6 \mathrm{ml}$ to $10 \mathrm{ml}$, increasing the speed at which the liquid cultures were shaken during the growth period from $250 \mathrm{rpm}$ to $350 \mathrm{rpm}$, and changing the growth media from a defined to a complex media in the form of Luria Broth (Fischer Scientific). All of these measures produced spectrophotometric data that resembled the assays shown in Figures 3 and 5 (data not shown).
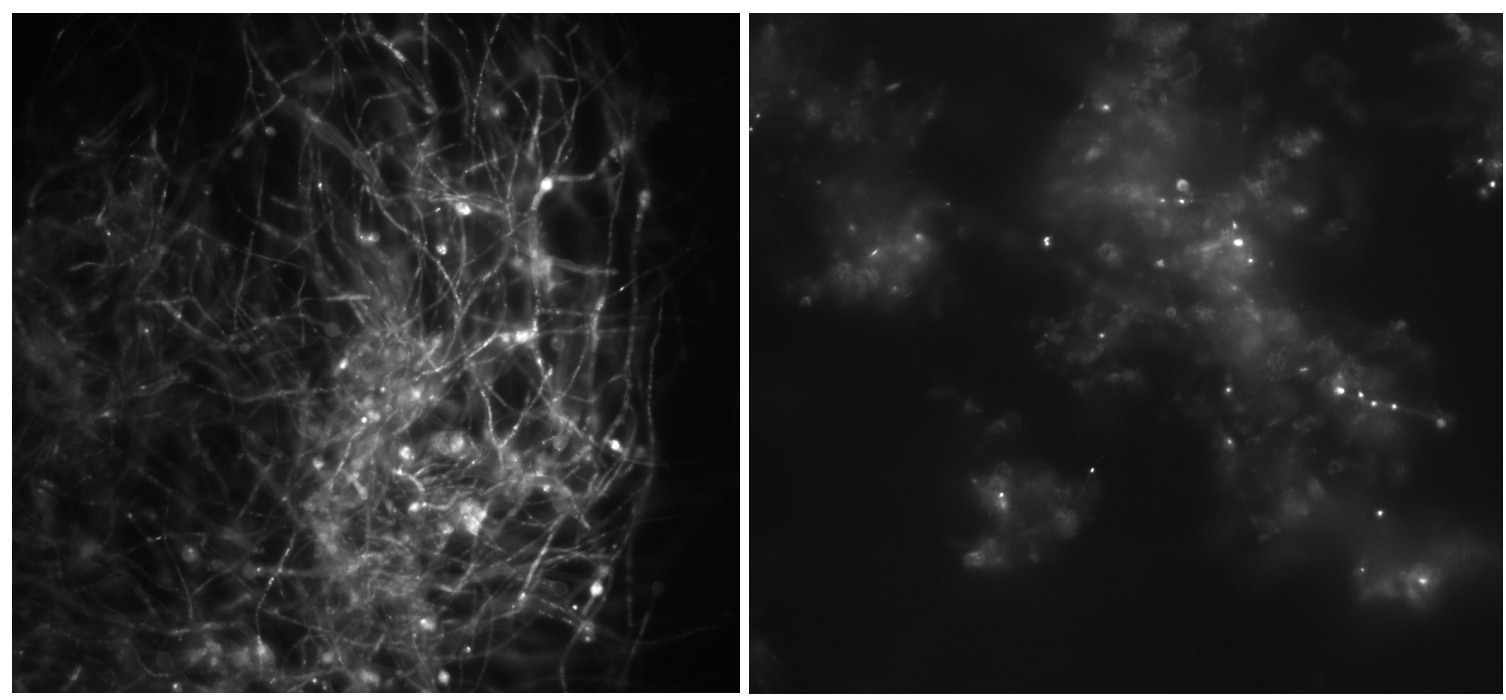

Figure 4. Mycelia stained with DAPI under fluorescent microscope. 4A (left) shows intact mycelia before shearing in the French Press. 4B (right) displays burst mycelia after shearing. 


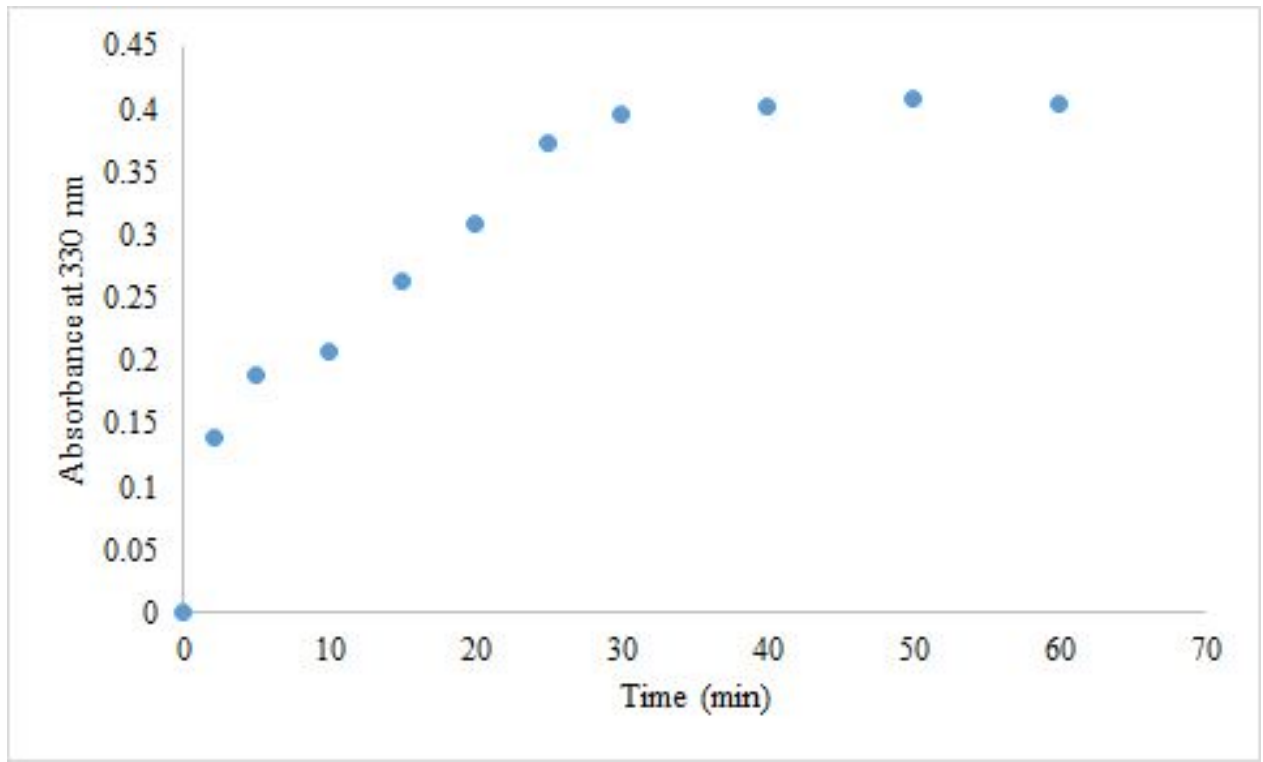

Figure 5. Second iteration of HGD enzyme assay after enhanced cell lysis methods. 100 ul of enzyme extract

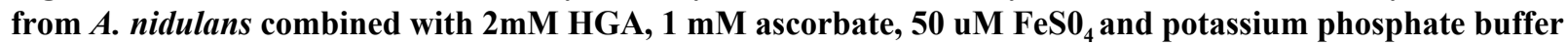
pH 7 , and placed in a $37^{\circ} \mathrm{C}$ water bath with oxygen bubbled in for 65 minutes.

In order to verify that the remaining reactants in the enzyme assay were operating as expected, an alternative source of enzyme was pursued. This took the form of a crude extract from FAH knockout mouse livers. These were not originally pursued as an enzyme source because they do not have the option of a strong induction of the Phe pathway through phenylacetic acid, which was one of the biggest appeals of the A. nidulans model [22, 23]. This means that the mouse livers do not produce as much of the required enzyme as the fungus. Nevertheless a protein extract was isolated via harvesting 4 mouse livers, homogenizing them in a solution of ice cold $0.14 \mathrm{M} \mathrm{KCl}$ added at $200 \% \mathrm{v} / \mathrm{v}$, centrifuging them at $5000 \mathrm{rpm}$ at $4{ }^{\circ} \mathrm{C}$, then centrifuging the supernatant at $20,000 \mathrm{~g}$ for 20 minutes at $4^{\circ} \mathrm{C}$. The assay used for this enzyme source was slightly different. The buffer used to bring the reaction to its final volume was $1 \mathrm{M}$ Tris at $\mathrm{pH} 7.4,50 \mathrm{mM}$ of ascorbate was added as opposed to the usual $100 \mathrm{mM}, 1.5 \mathrm{mM}$ of 
HGA, and no source of $\mathrm{Fe}^{2+}$ ions was added. Under these conditions, the mouse liver extract produced no detectable activity (Figure 6).

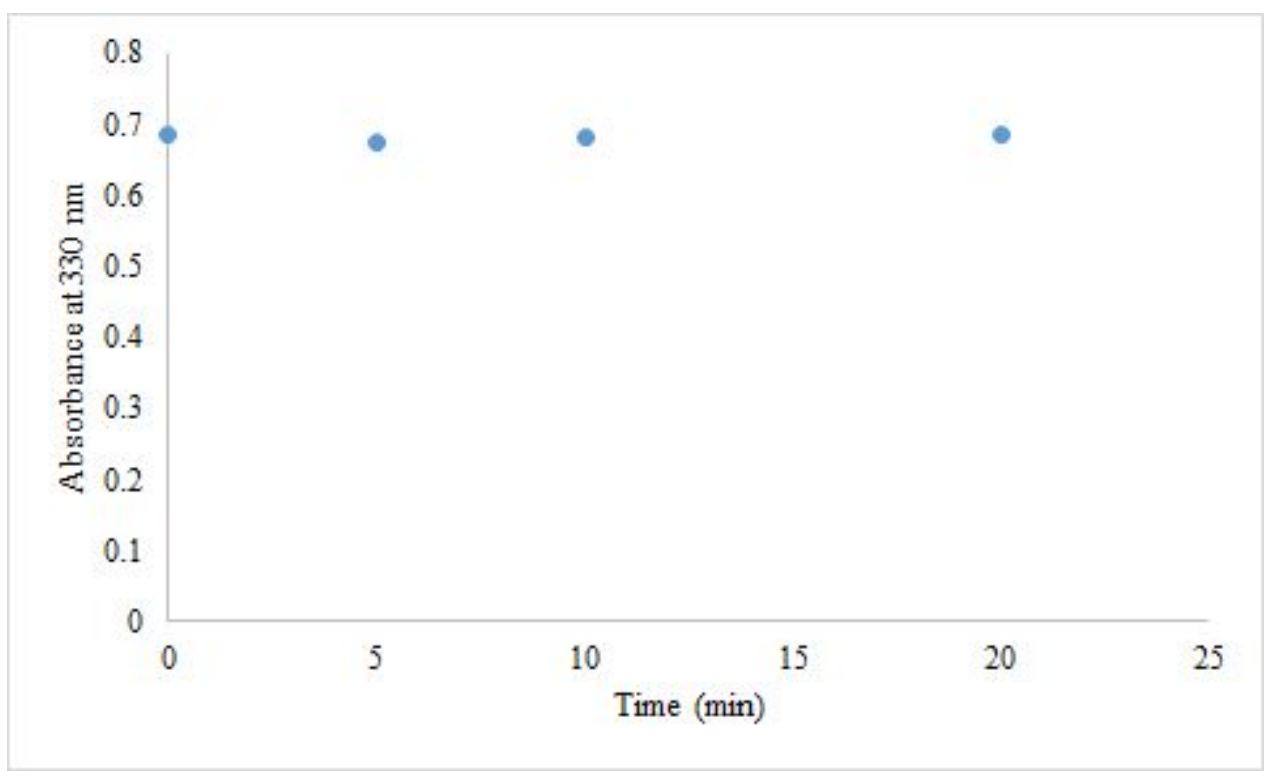

Figure 6. HGD enzyme assay using extract from fah (-/-) mouse liver. $1 \mathrm{ml}$ reaction contained $1 \mathrm{M}$ Tris at pH 7.4, $50 \mathrm{mM}$ ascorbate, and 1.5 $\mathrm{mM}$ of HGA. Reaction was stopped after 20 minutes due to no change in absorbance at $330 \mathrm{~nm}$ measured in the Nanodrop spectrophotometer.

Several more assays were run using fungal extracts and several variations on the reaction components, including trying a different buffer (Tris instead of potassium phosphate), eliminating Fe 2+ ions, and changing the concentration of the substrate HGA $(1.5 \mathrm{mM}, 2 \mathrm{mM}$ and $3 \mathrm{mM}$ ). None of these alterations produced an increase in enzyme activity as detected by the spectrophotometer (Data not shown). It was therefore hypothesized that perhaps the fungal spores, which had been stored at $-80^{\circ} \mathrm{C}$ for over 15 years, were too old to grow robustly and produce adequate amounts of enzyme. In order to address this potential problem, new protein extract and mycelium were obtained from the original architect of the protocol, Professor Fernández-Cañón, PhD. 
The new extract was used in the original assay protocol. Figure 7 displays the spectra at the beginning and end of the run as well as the change in absorbance over time. This assay showed very promising results. The appearance of a product peak at $330 \mathrm{~nm}$ indicated that there was high enzyme activity in the new extract. These data would suggest that problems with the previous assays were indeed an inadequate concentration of enzyme. All of the reactions up to this point had been pilot reactions that took place in $1 \mathrm{ml}$. The full reaction for the synthesis of large amounts of FAA takes place in a volume of $10 \mathrm{ml}$. 
A

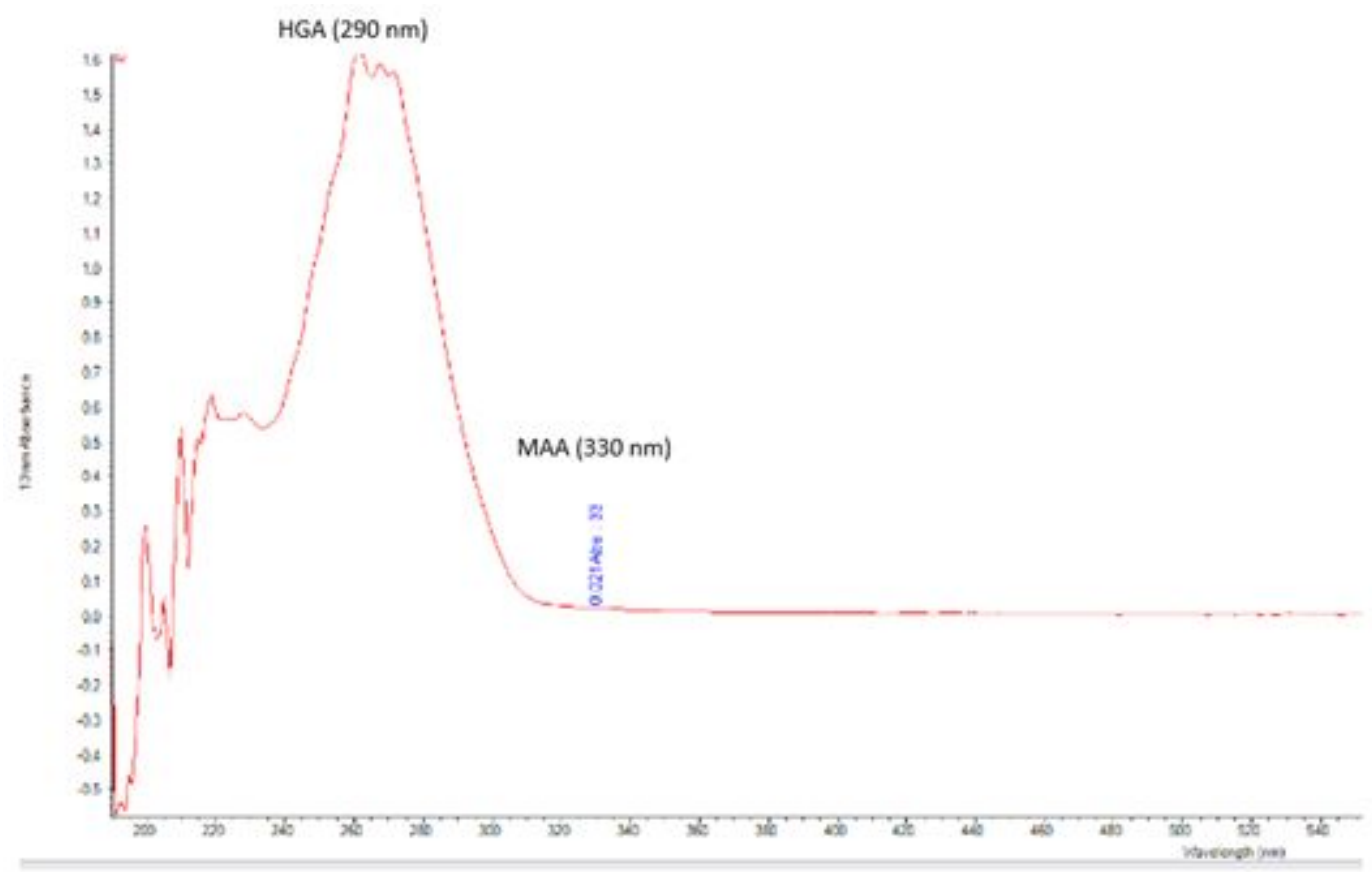

B

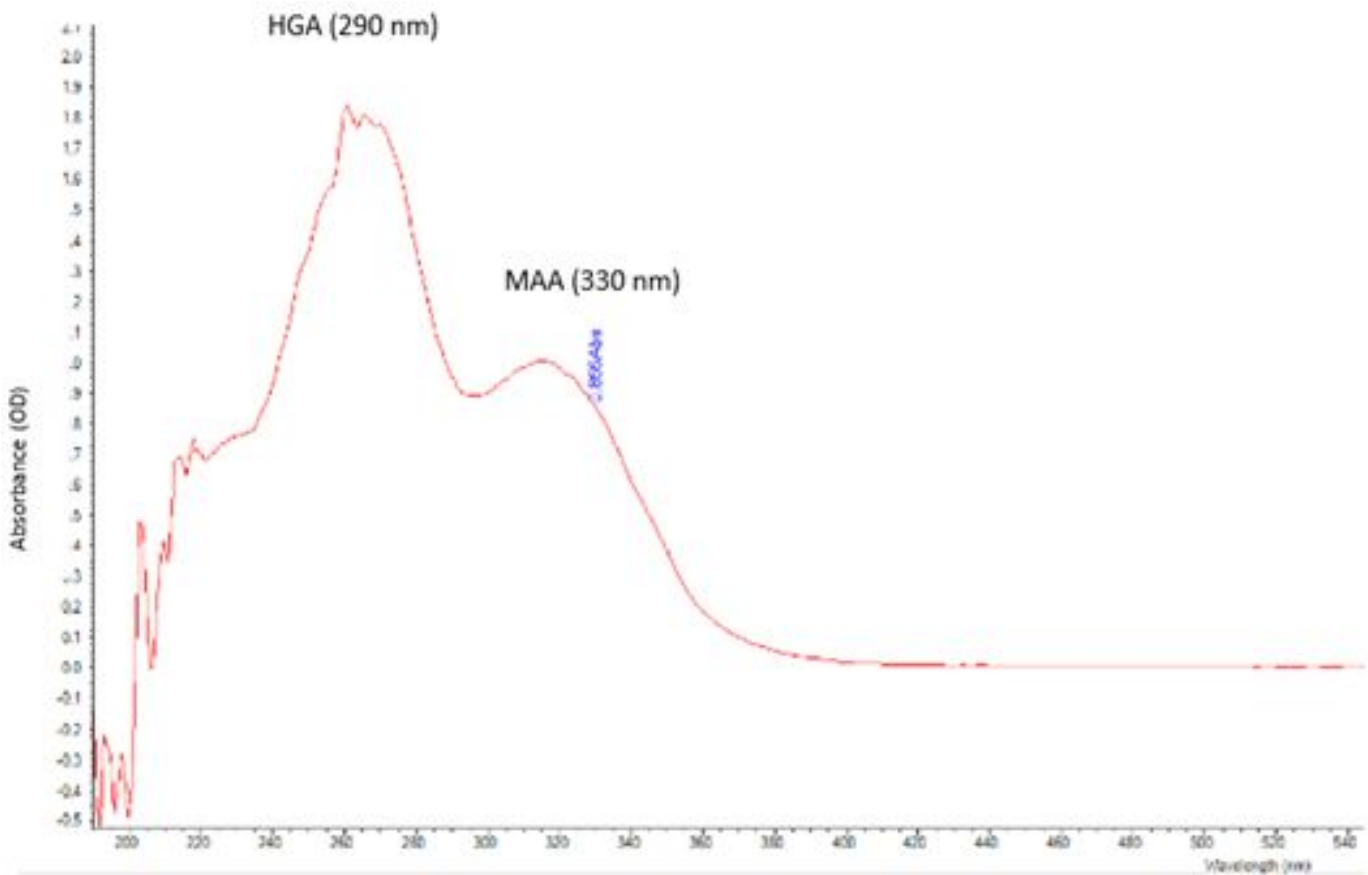


$\mathbf{C}$

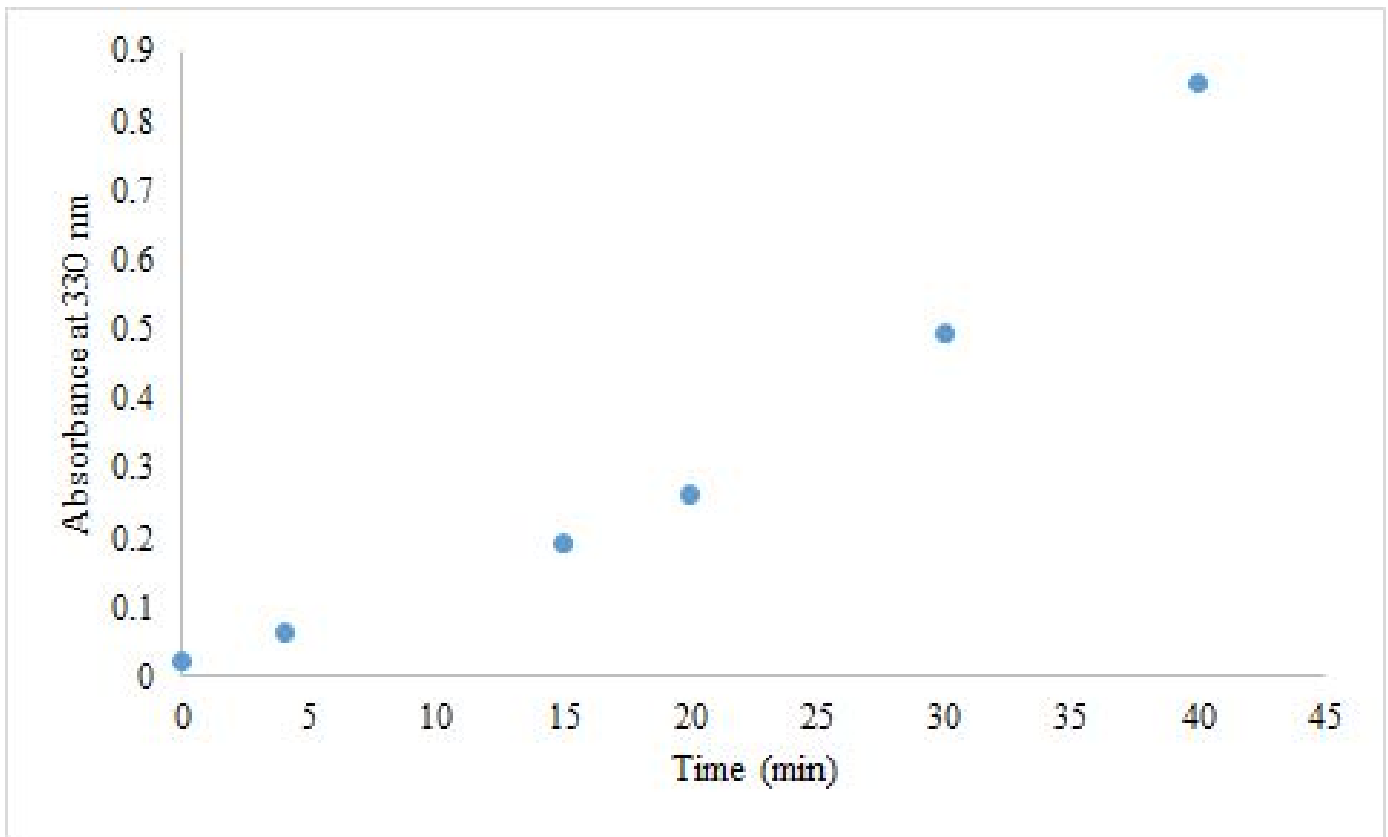

Figure 7. Enzyme assay for extract from Dr. Fernández-Cañón. 100 ul of enzyme extract from $A$. nidulans combined with $2 \mathrm{mM}$ HGA, $1 \mathrm{mM}$ ascorbate, $50 \mathrm{uM} \mathrm{FeS0}_{4}$ and potassium phosphate buffer $\mathrm{pH} 7$, and placed in a $37^{\circ} \mathrm{C}$ water bath with oxygen bubbled in for 40 minutes. Progress of the reaction was monitored in a Nanodrop spectrophotometer. (A) indicates spectrophotometric readout at the beginning of reaction with labels for peaks of the substrate (HGA) and the product (MAA). (B) indicates the spectrum of the enzyme assay at 40 minutes. $(C)$ displays the increase in absorbance at $330 \mathrm{~nm}$ over time.

After this successful pilot reaction, a larger scale reaction was attempted with the same enzyme source and reaction conditions. However, when the full scale reaction was run, there was once again no significant conversion of HGA to MAA (data not shown). Since it was clear from the data collected in the pilot reaction that there was significant activity in the enzyme extract (Figure 7), it was hypothesized that some aspect of the reaction setup was impeding the full size reaction. For example, the original protocol calls for bubbling oxygen into the reaction mixture continuously throughout the course of the assay, however due to the fact that bubbling has the potential to denature proteins, an alternative approach to adding oxygen to the reaction was pursued. This involved adding all of the reactants except for the protein extract into the reaction 
tube, pumping oxygen into the tube and dissolving it in the reaction mixture via vortexing. The reaction was also placed in a metal bead bath to maintain temperature at $37^{\circ} \mathrm{C}$ as opposed to the traditional water bath. The enzyme extract was then added and the reaction was monitored in the spectrophotometer after an additional modification step (Figure 8). Due to the fact that MAA will not absorb at $330 \mathrm{~nm}$ if it is in too alkaline of a $\mathrm{pH}$, the metaphosphoric acid, which is usually added after the reaction is complete, was added at a concentration of $10 \% \mathrm{v} / \mathrm{v}$ to the sample before the spectrum was obtained (Figure 8). As it apparent from the spectrum, there was no quantitative conversion of HGA to MAA. Another notable feature of the spectrum was the HGA peak, which is characteristically at $292 \mathrm{~nm}$ had shifted (Figure 8). This was very likely caused by the acidification of the mixture before it was placed in the spectrophotometer.

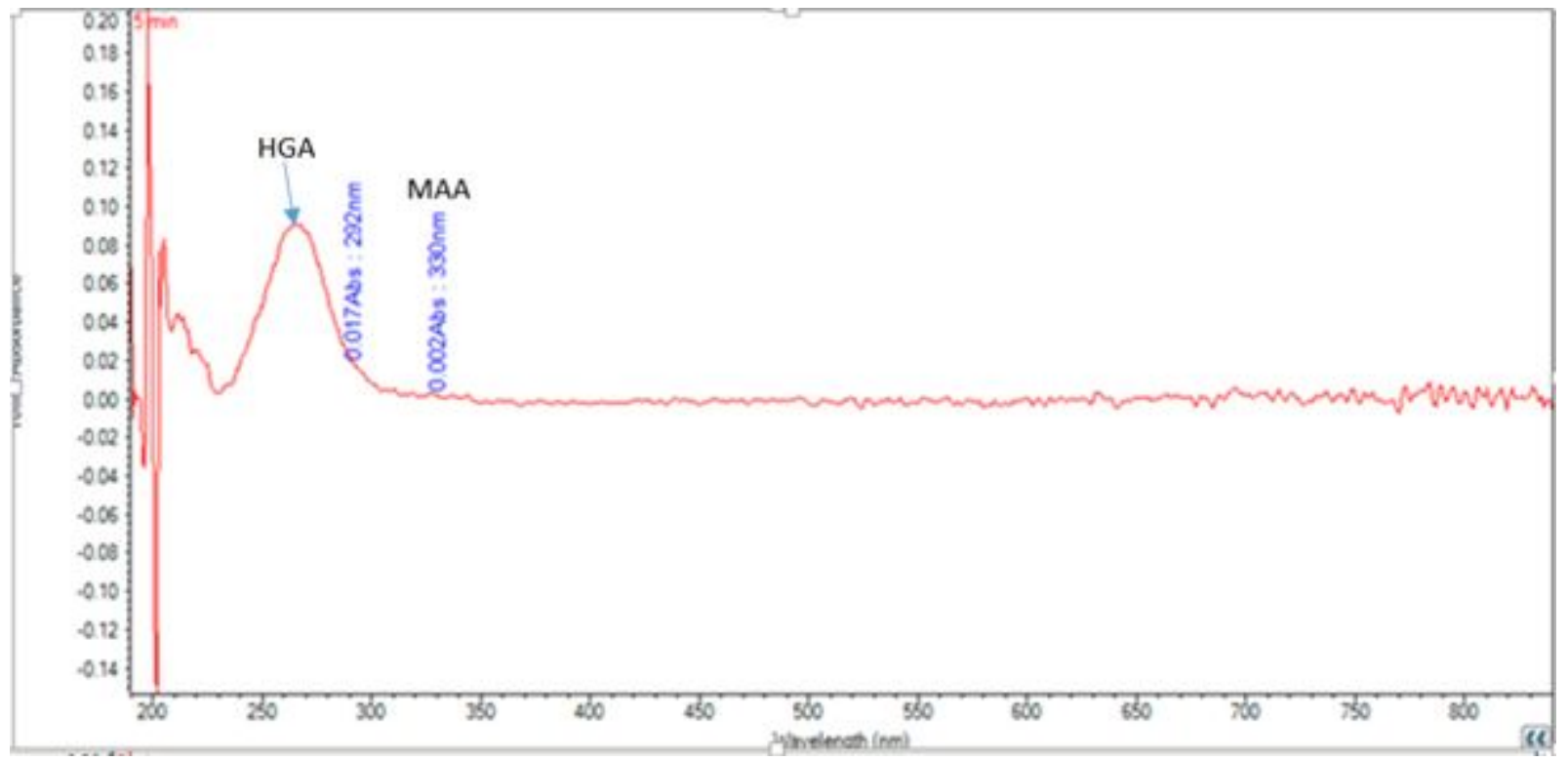

Figure 8. Spectrum of $10 \mathrm{ml}$ full size reaction mixture with extract from Dr. Fernández-Cañón. 2 mM HGA, 1 $\mathrm{mM}$ ascorbate, $50 \mathrm{uM} \mathrm{FeS0}_{4}$ and potassium phosphate buffer $\mathrm{pH}$ 7, added to reaction tube before oxygen gas was added and vortexed to dissolve oxygen in solution. 100 ul enzyme extract from A. nidulans then added. Reaction mixture placed in a $37^{\circ} \mathrm{C}$ metal bead bath for 60 minutes. MPA added at $10 \%$ v/v before readout. Note the shift in the HGA peak away from $290 \mathrm{~nm}$ most likely due to the addition of the acid. 
These results lead to the hypothesis that perhaps the enzyme extract was not concentrated enough to cause detectable conversion of HGA to MAA in the full scale reaction. According to Dr. Fernández-Cañón, the concentration of the extract should be around $10 \mathrm{mg} / \mathrm{ml}$. In order to determine the concentration of the experimental extract, a colorimetric protein quantification assay was used. The Bio-Rad assay uses Coomassie brilliant blue G-250 that binds to basic side chains on proteins in a sample and changes color at different protein concentrations. A set of controls with a known concentration of protein in a series of dilutions was compared to the experimental sample and the dilution that matched the experimental sample was taken as a rough estimate of the protein concentration of the sample. The concentration of the experimental extract appeared to be close to $1.5 \mathrm{mg} / \mathrm{ml}$, a drastic dilution from the $10 \mathrm{mg} / \mathrm{ml}$ expected. It was therefore determined that further concentration of the sample may have been necessary in order to obtain better activity in the enzyme assay.

Concentration of the extract was accomplished using the Amicon Ultra Centrifuge Filtration system. The filter used had a molecular weight cutoff (MWCO) of 5,000 da. $11 \mathrm{ml}$ of the enzyme extract was added to the filter and it was spun at $5,000 \mathrm{xg}$ at $4^{\circ} \mathrm{C}$ for 45 minutes to obtain a $10 \mathrm{x}$ concentration. The protein quantification assay was then rerun and the new concentration of protein was determined to be around $6 \mathrm{mg} / \mathrm{ml}$. Ideally, the sample would have been spun until the concentration was closer to $10 \mathrm{mg} / \mathrm{ml}$, however the protein began to precipitate out of solution, so the lower concentration was kept.

The new concentration was then used to rerun the assay under the new standard conditions. This assay once again came up with no activity after 60 minutes (Figure 9). This was the last assay run before the write up of this report. The lack of activity in this case could possibly be due 
to the killing off of the enzyme during a series of freezes and thaws, or due to precipitation during the concentration process.

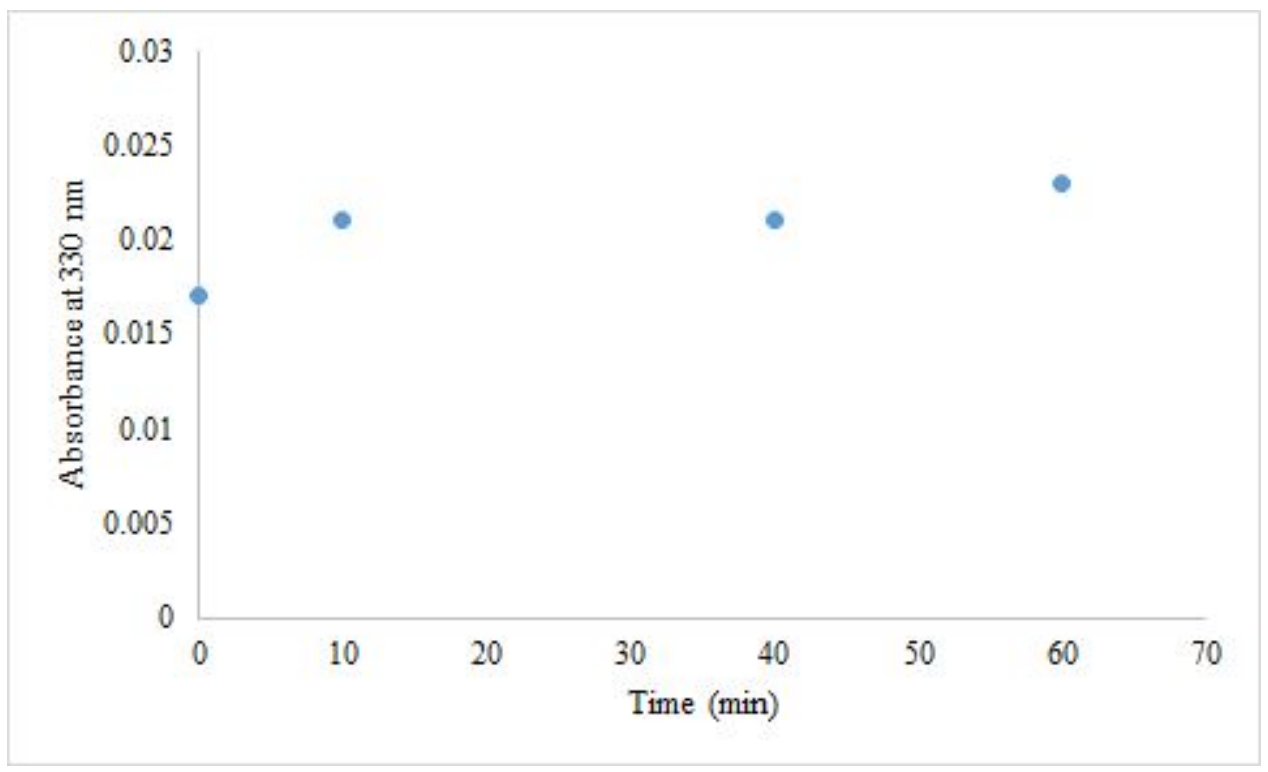

Figure 9. Change in absorbance at $330 \mathrm{~nm}$ over time of enzyme assay using extract concentrated in Amicon column. $2 \mathrm{mM}$ HGA, $1 \mathrm{mM}$ ascorbate, $50 \mathrm{uM} \mathrm{FeS0}_{4}$ and potassium phosphate buffer $\mathrm{pH}$ 7, added to reaction tube before oxygen gas was added and vortexed to dissolve oxygen in solution. 100 ul enzyme extract from $A$. nidulans then added. Reaction mixture placed in a $37^{\circ} \mathrm{C}$ metal bead bath for 60 minutes. MPA added at $10 \%$ v/v before readout.

\section{Discussion}

The failure of the assay to indicate any useful activity lead to several different troubleshooting approaches. The lack of activity could have been due to roughly three different error sources. The first approach assumed that something went wrong with the protein extract itself. This could have been an ineffective extraction method, denaturing of the enzyme during purification, or simply that there was not enough of the enzyme in the first place to reach levels of activity necessary for detection in the spectrophotometer. The second approach assumed an error in the reaction mixture, such as an improperly prepared buffer that is ineffective at maintaining optimal 
$\mathrm{pH}$, or too much or too little of one of the cofactors such as $\mathrm{Fe} 2+$ ions that are necessary for the enzyme to function. Finally, potential environmental influences such as temperature were addressed. Any or all of these error sources could be operating during any given iteration of the protocol. Troubleshooting methods were aimed at each of these three categories. Altering the growth conditions of the fungus and modifying the enzyme extraction methods had no effect on the quantitative conversion of HGA to MAA (Figure 5). Likewise obtaining the enzyme from mouse liver instead of fungi did not improve the performance of the assay (Figure 6). A extract from newer fungal samples showed promise in the initial phases, but its activity diminished over the course of several assays, even after concentrating the extract in an attempt to increase activity (Figure 7, 8, 9). Troubleshooting strategies aimed at the reaction mixture or environmental impacts also failed to produce extracts with higher yields of MAA. Since the only partly successful assay was run under the original reaction conditions, with the literature recommended buffer system it seems most likely that the source of error in the experiment is that there has not yet been a source of enzyme that provides high enough activity for quantitative conversion to take place.

The next step is to continue to pursue better enzyme sources. Dr. Fernández-Cañón provided us with new mycelia that have been enzymatically induced and harvested. These newer spores are a promising source of enzyme as is apparent by the partial success of the reaction with the first use of the protein extract made from the same source (Figure 7). Another future approach could potentially be an attempt to clone the $h g d$ gene from $A$. nidulans into an organism that would lend itself to a less fraught induction and extraction process. 
The original intent of this thesis was to seek out ways to optimize and improve the original FAA synthesis protocol. Due to the difficulty experienced herein, this is still a valid research goal. If the protocol can be successfully replicated, then ways to streamline this process are well worth pursuing in order to have stores of FAA to be used in assays testing CEHPOBA, a drug that has potentially vast therapeutic benefits [5]. 


\section{References}

1. Lee, C.-H. A Simple Outline of Methods for Protein Isolation and Purification. Endocrinol Metab (Seoul) 32, 18-22 (2017).

2. Elgilani, F. et al. Chronic Phenotype Characterization of a Large-Animal Model of Hereditary Tyrosinemia Type 1. American journal of pathology, The American journal of pathology, The American journal of pathology. 187, 33-41 (2017).

3. Harding, C. O. Gene and Cell Therapy for Inborn Errors of Metabolism. in Inherited Metabolic Diseases 155-171 (Springer, Berlin, Heidelberg, 2017).

doi:10.1007/978-3-662-49410-3_22

4. Blackburn, P. R. et al. Silent Tyrosinemia Type I Without Elevated Tyrosine or Succinylacetone Associated with Liver Cirrhosis and Hepatocellular Carcinoma. Human mutation, Human mutation. 37, 1097-1105 (2016).

5. Nygaard, S. et al. A universal system to select gene-modified hepatocytes in vivo. Sci Transl Med 8, 342 ra79 (2016).

6. KaiserJun. 8, J., $2016 \&$ Pm, 2:30. How a liver-damaging drug may give a boost to gene therapy. Science | AAAS (2016). Available at:

http://www.sciencemag.org/news/2016/06/how-liver-damaging-drug-may-give-boost-ge ne-therapy. (Accessed: 25th October 2017)

7. Harding, C. O. et al. Pharmacologic inhibition of L-tyrosine degradation ameliorates cerebral dopamine deficiency in murine phenylketonuria (PKU). J Inherit Metab Dis 37, 735-743 (2014). 
8. Tang, Y.-C. \& Amon, A. Gene copy number alterations: A cost-benefit analysis. Cell 152, 394-405 (2013).

9. Blackwell, M. The Fungi: 1, 2, 3 ... 5.1 million species? Am. J. Bot. 98, 426-438 (2011).

10. Flipphi, M. et al. Biodiversity and evolution of primary carbon metabolism in Aspergillus nidulans and other Aspergillus spp. Fungal Genetics and Biology 46, S19-S44 (2009).

11. Gresham, D. et al. The Repertoire and Dynamics of Evolutionary Adaptations to Controlled Nutrient-Limited Environments in Yeast. PLoS Genet 4, (2008).

12. Jin, J., Lee, Y.-K. \& Wickes, B. L. Simple Chemical Extraction Method for DNA Isolation from Aspergillus fumigatus and Other Aspergillus Species. J Clin Microbiol 42, 4293-4296 (2004).

13. Nguyen, T. H. \& Ferry, N. Liver gene therapy: advances and hurdles. Gene Ther 11, S76-S84 (2004).

14. Al-Dhalimy, M., Overturf, K., Finegold, M. \& Grompe, M. Long-Term Therapy with NTBC and Tyrosine-Restricted Diet in a Murine Model of Hereditary Tyrosinemia Type I. $M G M 75,38-45$ (2002).

15. Berg, J. M., Tymoczko, J. L. \& Stryer, L. The Purification of Proteins Is an Essential First Step in Understanding Their Function. (2002).

16. Wingfield, P. T. Protein Precipitation Using Ammonium Sulfate. Curr Protoc Protein Sci APPENDIX 3, Appendix-3F (2001). 
17. Aponte, J. L. et al. Point mutations in the murine fumarylacetoacetate hydrolase gene: Animal models for the human genetic disorder hereditary tyrosinemia type 1. Proc Natl Acad Sci U S A 98, 641-645 (2001).

18. Manning, K., Al-Dhalimy, M., Finegold, M. \& Grompe, M. In vivo suppressor mutations correct a murine model of hereditary tyrosinemia type I. Proc Natl Acad Sci U S A 96, 11928-11933 (1999).

19. Adams, T. H., Wieser, J. K. \& Yu, J.-H. Asexual Sporulation in Aspergillus nidulans. Microbiol. Mol. Biol. Rev. 62, 35-54 (1998).

20. Fernández-Cañón, J. M. \& Peñalva, M. A. Characterization of a Fungal Maleylacetoacetate Isomerase Gene and Identification of Its Human Homologue. J. Biol. Chem. 273, 329-337 (1998).

21. Granadino, B., de Bernabé, D. B.-V., Fernández-Cañón, J. M., Peñalva, M. A. \& de Córdoba, S. R. The Human Homogentisate 1,2-Dioxygenase (HGO) Gene. Genomics 43, 115-122 (1997).

22. Fernández-Cañón, J. M. \& Peñalva, M. A. Spectrophotometric Determination of Homogentisate Using Aspergillus nidulans Homogentisate Dioxygenase. Analytical Biochemistry 245, 218-221 (1997).

This article details a procedure for the spectrophotometric detection of A. nidulans homogentisate 1,2 dioxygenase (HGO) activity. The enzyme assay detects the conversion of homogentisate (HGA) to maleylacetoacetate (MAA) by the appearance of a peak at OD 330 nm. Fernández-Cañón and Peñalva detail the growth of A nidulans under conditions that induce the phenylalanine pathway and illustrate that is preparation produces high enzyme activity than previous rat and mouse models. The authors also show that the activity of the HGO enzyme is highly substrate specific by adding similar aromatic compounds to HGA and showing that they do not impact the formation of the 330 MAA peak. Fernández-Cañón 
and Peñalva present this assay as an alternative clinical detection method for alkaptonuria in human patients, as well as applications in bacterial and plant biology.

23. Fernández-Cañón, J. M. \& Peñalva, M. A. Molecular Characterization of a Gene

Encoding a Homogentisate Dioxygenase from Aspergillus nidulans and Identification of

Its Human and Plant Homologues. J. Biol. Chem. 270, 21199-21205 (1995).

This paper details the discovery of a gene encoding homogentisate dioxygenase, $h m g A$, in the organism Aspergillus nidulans, as well as characterization of its human and plant homologues. This gene codes for an enzyme that is significant in the metabolic pathway for the breakdown of phenylalanine in humans and A. nidulans. Fernández-Cañón and Peñalva argue that $A$ nidulans is a good model organism for studying this pathway in humans because the pathway is very similar in both organisms and A nidulans has been used in the characterization of other enzymes in that same pathway. The authors created a cDNA library of all the genes that were induced by growing the fungus in phenylacetic acid as the sole carbon source. They sequenced the gene and used Northern blotting to isolate the gene. Fernández-Cañón and Peñalva argue that the gene is the one they claimed based on the following: the transcription pattern found in the Northern blot experiments was consistent with genes previously identified in the Phe/PhOAc catabolic pathway; no transcription of the identified sequence was detected when the fungus was grown in the absence of Phe/PhOAc; the gene was found to be close to a previously detected gene encoding an enzyme in the same pathway; cells where the gene had been disrupted via plasmid insertion were not able to grow in Phe/PhOAc as the sole carbon source and secreted homogentisate (which appeared as red pigment) when grown in a Phe/PhOAc. This pigment secretion is also present in alkaptonuria, the disorder in humans that results in a build up of homogentisate.

24. Schmidt, S. R., Müller, C. R. \& Kress, W. Murine Liver Homogentisate 1,2-Dioxygenase. European Journal of Biochemistry 228, 425-430 (1995).

25. Knox, W. E. \& Edwards, S. W. Homogentisate Oxidase of Liver. J. Biol. Chem. 216, 479-488 (1955).

26. "Ammonium Sulfate Precipitation Protocol | Exalpha Biologicals, Inc." 
27. Timberlake, W.E. \& Marshall M.A. Genetic regulation of development in Aspergillus nidulans. Trends in Genetics. 4,162-169 (1988).

28. Fernández-Cañón, J. M. \& Peñalva, M. A. Fungal metabolic model for human type I hereditary tyrosinemia. Proc. Natl. Acad. Sci. USA 92, 9132-9136 (1995).

29. Grompe, M. Principles of therapeutic liver repopulation. J. Inherit. Metab. Dis. 29, 421-425 (2006). 